\title{
PARATEXTOS DE LA TRADUCCIÓN AL ESPAÑOL DE LIFE IN MEXICO DE FRANCES CALDERÓN DE LA BARCA: (PARA)TRADUCIR LA PROPIA IDENTIDAD
}

\author{
PARATEXTS OF THE SPANISH TRANSLATION OF LIFE IN \\ MEXICO BY FRANCES CALDERÓN DE LA BARCA: (PARA) \\ TRANSLATING OF THE SELF-IDENTITY
}

\author{
Olivia Correa Larios* \\ Verónica del Carmen Murillo Gallegos*
}

\section{RESUMEN}

Frances Calderón de la Barca escribió en inglés sus impresiones sobre México en correspondencia privada sostenida entre 1838 y 1841, periodo en que residió en el país con su esposo, el primer embajador de España en México. Una selección de sus cartas conformó el libro Life in Mexico, publicado en 1843 en Boston y en Londres. La publicación de la obra, que incluía algunas descripciones negativas de las ciudades, la sociedad, la moda, la comida e incluso el aspecto físico de algunos mexicanos, dio lugar a traducciones mexicanas de fragmentos entre 1843 y 1844 , traducciones completas en 1920 y 1959 y finalmente una traducción completa española en 2007. Todas estas traducciones estuvieron rodeadas de peritextos y epitextos en los que los editores comentaron la obra de Calderón de la Barca. En este contexto, la traducción de la obra nos permite reflexionar sobre los encuentros interculturales, puesto que, en sus textos, los viajeros exponen el encuentro con el otro y, las traducciones en las tierras de las que se ocupan, exponen una redefinición del yo y del nosotros como yo colectivo. En este trabajo se propone una revisión de los elementos paratextuales de las traducciones de Life in Mexico a la luz de la noción de paratraducción, que nos consiente la reflexión en torno a las acciones de los agentes paratraductores para manifestar que, cuando dentro de lo que se traduce está en juego la propia identidad, los paratextos revelan unas prácticas editoriales que van de la censura, a la polémica y al elogio con el pasar de las décadas.

Palabras clave: paratraducción, literatura de viajes, México decimonónico.

\section{ABSTRACT}

Frances Calderón de la Barca wrote her impressions of Mexico in English in private correspondence held between 1838 and 1841, the period in which she resided in the country with her husband, the first Spanish ambassador to Mexico. A selection of her

\footnotetext{
* Universidad Autónoma de Zacatecas, México.ocorrealarios@gmail.com Orcid: https://orcid.org/0000-0002-2545-2674

** Universidad Autónoma de Zacatecas, México. veramurillog@gmail.com Orcid: https://orcid.org/0000-0002-7561-3771
} 
letters constitutes the book Life in Mexico, published in 1843 in Boston and London. The publication of the work, which included some negative descriptions of cities, society, fashion, food and even the physical appearance of some locals, led to Mexican translations of fragments of the work between 1843 and 1844, complete translations in 1920 and 1959. and another complete translation published in Spain in 2007. Each of these translations was surrounded by peritexts and epitexts in which the editors commented on the work of Calderón de la Barca. In this context, the translation of Life in Mexico allows us to reflect on intercultural encounters, since, in their texts, travelers expose the encounter with the other and, translations in the lands they deal with, expose a redefinition of the self and of us as a collective self. This paper proposes a review of the paratextual elements present in the translations of Life in Mexico in light of the notion of paratranslation. This notion allows us to reflect on the actions of paratranslation agents in order to conclude that when the identity itself is at stake in the text to be translated, then the paratexts reveal some editorial practices that range from censorship, to controversy, to praise over the decades.

Keywords: paratranslation, travel literature, $19^{\text {th }}$ century Mexico.

\section{INTRODUCCIÓN}

La escocesa Frances Erskine Inglis, conocida como Madame Calderón de la Barca por su matrimonio con el primer diplomático español en el México independiente, Ángel Calderón de la Barca, escribió sus impresiones sobre el país en correspondencia privada a sus familiares y amigos entre 1838 y 1841 . Cincuenta y cuatro de sus cartas con agudas observaciones sobre la sociedad integraron el libro Life in Mexico, que fue publicado en Boston y en Londres en 1843. En México, la publicación dio lugar a traducciones parciales rodeadas de peritextos y epitextos en los que los agentes paratraductores comentaron la obra de la escocesa.

En este contexto, el estudio de la literatura de viajes nos permite reflexionar sobre los encuentros interculturales, puesto que las obras exponen el encuentro con el otro y, sus traducciones en las tierras de las que se ocupan, una redefinición del yo y del nosotros. De la misma manera en que los desplazamientos consienten el conocimiento de las diferentes culturas y es innegable que la observación se realiza desde un lente sociocultural de quien se desplaza, así mismo, la traducción de los relatos de viajeros se realiza desde una perspectiva subjetiva en la manera en que se afronta el texto a traducir.

En este trabajo se propone una revisión de los elementos paratextuales de las primeras traducciones mexicanas de la obra en 1843 y 1844, publicadas por entregas en periódicos locales, así como de las traducciones del texto completo publicadas en 1920, 1959 en México y 2007 en España. Esta revisión se hace a la luz de la noción de paratraducción, nacida en la Universidad de Vigo, la cual nos permite explorar la acción de los agentes de paratraducción. En un ámbito en el 
que lo que se traduce es la propia identidad, la paratraducción del texto revela unas prácticas editoriales que van de la censura, a la polémica y al elogio con el pasar de las décadas.

\section{LA LITERATURA DE VIAJES}

La literatura de viajes, más allá de dar cuenta de un movimiento en el espacio geográfico, representa una exploración, aunque sea parcial, de la propia realidad puesta frente a una realidad diferente. Los motivos de los autores-viajeros son tan variados como las condiciones en las que se lleva a cabo el viaje, por eso, la exploración resultante del alejamiento de lo propio y de visión de lo otro difiere también entre distintos momentos, viajes y viajeros. Esa heterogeneidad se refleja en que los relatos de viajeros tienen múltiples formas discursivas que, de acuerdo con Colombi Nicolia (2006), ya sean productos de peregrinaciones, conquistas, exploraciones, turismo, etc., sus procedimientos se acercan más a la narrativa que a la descripción metódica. Aún en la diversidad de este género, la literatura de viajes tiene como elementos cohesivos de sus textos el tema del desplazamiento, el narrador como protagonista del viaje y la suposición de veracidad por parte del mismo sobre sus observaciones (COLOMBI NICOLIA, 2006).

De acuerdo con López de Mariscal (2014), estudiar la literatura de viajes es una vía para entender la historia de los encuentros interculturales, ya que su contenido, al implicar necesariamente el encuentro con el otro, es también una redefinición del yo y del nosotros. El interés en el otro está determinado por la percepción de las diferencias y esa percepción es producto del entramado del propio bagaje cultural y lo desconocido en la experiencia del viaje. Como explica Ette (2008), a lo largo del tiempo, los relatos de viaje han gozado de buena recepción y distribución ya que su lectura es, a su vez, una forma de viajar y emprender la experiencia del descubrimiento del otro que propone el viajero escritor.

Según Romano Sued (2014), el viaje es un escenario de representación tanto de la identidad como de la alteridad. El componente ideológico de los viajeros, conformado por su procedencia y el propósito de su viaje, tiene una fuerte influencia sobre las características y las funciones de sus relatos. Ejemplo de lo anterior lo ilustra Ette (2008) al exponer que entre los siglos XVI y XIX, la literatura de viajes relativa a Latinoamérica constituyó la base de construcción del conocimiento al servicio de los intereses y las ideologías coloniales europeas. Es innegable que los viajes permiten observar la civilización, las formas de vida de diferentes culturas, como es también incuestionable que la observación se realiza desde el estado social, 
cultural y económico del contexto de origen del viajero. Por ello, las duras críticas que se encuentran en numerosos testimonios de viajeros europeos en México dan muestra de que el lente con que se mira relativiza lo observado. En palabras de Lilián Illades (2019), los viajeros "a partir de su civilizada visión calificaron de bárbaro al pueblo que habían visitado" (s.p.).

Illades (2019), Ortega y Medina (2015) y Covarrubias (1998) atribuyen el inicio del interés por el emprendimiento de negocios en México a la idea, quizás exagerada, de prosperidad futura plasmada en el exitoso libro que en 1811 publicó Alexandre Humboldt Ensayo político sobre el reino de la Nueva España, que fue traducido al inglés y reeditado reduciéndolo a la información estrictamente minera y comercial. Costeloe (2006) da también crédito al libro Six months' residence and travels in Mexico que, inspirado por Humboldt y por la novedad de la recién obtenida independencia de México, William Bullock publicó en 1824, que fue un éxito traducido casi inmediatamente al francés y al holandés y que motivó a numerosas compañías extranjeras que se establecieron en México (entre el amplio rango de alternativas geográficas del que podían elegir) con el objetivo de explotar los recursos naturales del país.

\section{LA TRADUCCIÓN DE LITERATURA DE VIAJES EN EL MÉXICO DECIMONÓNICO}

Como expone Castro (2019), los estudios de traducción han sobrepasado los enfoques dicotómicos de comparaciones entre el texto original y el texto traducido para dar lugar a considerar la traducción como una práctica discursiva socio-histórica. Para la autora, la traducción en la historia de Centroamérica ha tenido una importante injerencia tanto en la adopción y adaptación de conceptos e ideologías políticas, como en la consolidación de medios culturales y literarios. En el caso de México, la autora expone que la práctica traductora en los primeros años de independencia se hace evidente en los catálogos bibliográficos de los editores mexicanos, pues estos enlistan numerosos títulos en lenguas extranjeras, sobre todo en francés, y no menos traducciones al español. La lectura en otros idiomas y la práctica traductora eran actividades comunes a los intelectuales mexicanos decimonónicos que evidenciaron en sus contribuciones en periódicos y revistas literarias.

A partir de la mitad del siglo XX se presenta en Latinoamérica una numerosa producción editorial y académica relativa a la literatura de viajes del siglo XIX, sin embargo, el rol de la traducción de dicha literatura en las primeras décadas de vida independiente de las colonias es aún un campo poco explorado en la academia. 
Ramírez Rodríguez (2013) afirma que en México ha sido muy poco abordada la traducción como espejo de identidad, es decir, como proceso que representa un puente entre la percepción extranjera de lo mexicano y la formación de imagen de nación y el autorreconocimiento por parte de los mexicanos. Si la literatura de viajes y su traducción contribuyó a modelar la imagen del país para lectores extranjeros y mexicanos, ejerció efectivamente un papel de puente. Pero, siguiendo a Cronin (2006), los puentes separan tanto como unen y esta imagen es transferible a la traducción: si las traducciones son medios de difusión que pueden llevar una carga ideológica de una cultura a otra, también son medios de separación por la misma carga.

La interpretación de aspectos de relaciones de poder y de construcción de la imagen del otro es parte del proceso de traducción tanto como lo es de la escritura de relatos de viaje. De acuerdo con Carneiro Rodrigues (2008), al construir imágenes de culturas, ambas actividades presentan el fenómeno de la apropiación de los pueblos y culturas. Este fenómeno se acentúa cuando el relato de viaje de un extranjero se traduce para el habitante del país al que el relato se refiere. La imagen presente en el texto no retrata una cultura ajena, sin embargo, el lector tampoco encuentra en ella su propia realidad, sino una construida desde la otredad. Como hemos explorado en otros trabajos, (CORREA LARIOS, 2018; CORREA LARIOS; HARKINS KENNING, 2018) en la primera mitad del siglo XIX existía en México un interés por lo que los viajeros extranjeros escribían sobre el país, lo cual permeaba en la práctica traductora, que se convertía en puente para unir y para separar al influir en los lectores sobre la percepción del propio país.

Dos Santos y Alvarado (2013) advierten que explorar el papel de la traducción en la historia conlleva el riesgo de desviar el discurso hacia la asunción de que la labor del traductor es juzgada como incorrecta sin ahondar sobre las motivaciones ideológicas que separan el texto original y el traducido. Con el objeto de distanciarnos de esa asunción, se presentan algunas perspectivas y algunos conceptos que sirvieron para la realización de este análisis.

Garrido Vilariño (2007) expone que es posible identificar en los textos traducidos las manipulaciones producto del deber o el deseo de conformidad con las normas del contexto social meta. Esta conformidad tiene causas ideológicas que pueden resultar en modificaciones que van de mínimos cambios estilísticos a cambios de lectura e interpretación. De acuerdo con el autor: "en el sistema receptor de una traducción se tiene una idea sobre la función que debe cumplir una traducción en su seno; el editor tiene una idea sobre cómo presentar un bien cultural a su público y el traductor tiene una idea sobre cómo tiene que traducir (2007, p. 54). 
Como ya se dijo, el traductor y el viajero no son únicamente individuos, sino agentes de una colectividad. Esto es, su actividad cumple funciones ideológicas al servicio de la consolidación de posturas en torno a las identidades colectivas de su propio grupo y del grupo que se presenta ante ellos en el texto y en el viaje. Por lo tanto, como explica Romano Sued (2014) la traducción disemina un discurso social subjetivo, mediado por las instituciones de la sociedad que la produce. Los productos escritos por viajeros y traductores son, pues, un vehículo de ideologías, de valores del entorno social y temporal al que pertenecen.

La individualidad de los traductores no es lo que interesa en este artículo, sino los aspectos contextuales que conforman la ideología desde la que se produjo la traducción, puesto que, como afirma Payás (2013), la traducción ejerce funciones

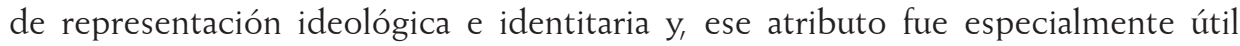
en la formación de identidad colectiva en Latinoamérica tras los procesos de independencia. Si bien, las nuevas naciones latinoamericanas no podían influir en la imagen que la literatura extranjera construía de ellas, sí les fue posible confrontarla a través de la publicación de traducciones de textos de viajeros en periódicos y revistas locales, que solían estar rodeadas de peritextos y epitextos.

Proyectos editoriales como El álbum mexicano y El museo mexicano dedicaron varias de sus páginas a advertir a sus lectores sobre lo que desde la perspectiva local parecía una oscura intención por parte de extranjeros malévolos, por lo que, a través de la publicación de traducciones de textos de viajeros, refutaban las críticas y resaltaban los aspectos positivos del país (CORREA LARIOS, 2018).

\section{DEL PARATEXTO A LA PARATRADUCCIÓN}

La consideración de los paratextos dentro de la disciplina de la traducción se hace presente en trabajos e investigaciones de índole práctico y teórico que exploran la relación entre el texto y su entorno constituido por dispositivos paratextuales unidos o no físicamente a él. El paratexto, según el modelo de Gérard Genette (1997) es un elemento que rodea al texto, lo extiende, lo presenta y asegura su presencia, su recepción y su consumo. Este elemento actúa como un umbral para entrar o bien para alejarse del texto. Para Genette, la naturaleza de los elementos paratextuales, sean estos peritextos o epitextos, está vinculada a la intención autorial, es decir, las funciones que realizan los paratextos con miras a la existencia del texto y a su recepción están orientadas a influir positivamente en su consumo, en asegurar una lectura más pertinente desde la perspectiva de lo que esperan el autor y la editorial. Esta premisa que prioriza la intención no es 
exclusiva del texto original y su editor, ya que una traducción es un texto que está rodeado, presentado, comentado y extendido por sus propios paratextos. De modo que, anticipando lo que sucede en el objeto de estudio que aquí nos ocupa, en la historia de la traducción podemos encontrar intenciones autoriales y editoriales que difieren de las del texto original y que producen elementos paratextuales desde la perspectiva de un "nada inocente acto de traducir" (YUSTE FRÍAS, 2015, p. 334) que asegure el consumo pertinente del texto traducido.

Batchelor (2018), también con base en el concepto de Genette, aborda el problema de la intención autorial explicando que dentro de los estudios de traducción, la definición de paratexto de textos traducidos no depende de los designios del autor o del editor originales, sino que, dentro de la disciplina, el criterio para construir un corpus de elementos paratextuales es la consideración de si dichos elementos realizan funciones paratextuales. Con ello, la autora admite epitextos que Genette no denominaría paratextos, tales como comentarios por parte del público receptor del texto expresados en medios que no están vinculados al autor o al editor. Si bien Genette excluye este tipo de epitextos del concepto de paratextos por no incluir una asunción de responsabilidad y de intención por parte del autor, reconoce que estos elementos pueden acercar lectores a los textos, con lo que reconoce que enmarcan y dan forma a la experiencia lectora. Nos permitimos estas digresiones y aclaraciones de sentido, en primer lugar, porque nuestro objeto

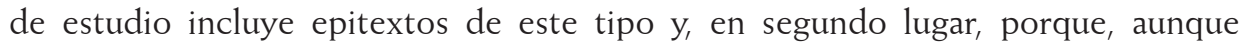
Batchelor llega a desaconsejar el uso de la noción de paratraducción, observamos que, incluso dentro de su marco conceptual, es comprobable la pertinencia de esta noción en la traductología.

A partir del concepto de paratexto de Genette, el grupo de investigación Traducción \& Paratraducción de la Universidade de Vigo, dirigido por José Yuste Frías, ha propuesto la noción de paratraducción, que supera el ámbito de los estudios literarios para abrir la posibilidad de "analizar y estudiar las implicaciones estéticas, políticas, ideológicas, culturales y sociales de cualquier tipo de paratexto en traducción" (YUSTE FRÍAS, 2015, p. 321). De acuerdo con Yuste Frías (2011), la paratraducción es una noción terminológica formulada con el propósito de estudiar en el ámbito de la traducción los elementos paratextuales que presentan, introducen, prolongan, acompañan y aseguran la existencia, recepción y consumo de un texto, sean estos elementos entidades verbales, icónicas o verbo-icónicas. El desarrollo conceptual de la paratraducción está ligado a la observación de Garrido Vilariño (2012), quien denuncia una negligencia por parte de los estudiosos de la traducción al ignorar la descripción de agentes de paratraducción tales como los 
editores y los revisores, que son actores que deciden la introducción de géneros o de autores extranjeros en una cultura local, además de la manera en que se presenta y se interpreta al otro desde la perspectiva sociocultural del contexto receptor en un momento dado. Dentro del proceso editorial, son esos paratraductores los que definen cómo se lleva a cabo la traducción, qué partes son traducidas y qué partes omitidas.

La noción de paratraducción propone, entonces, llamar la atención sobre la lectura, la interpretación y la traducción de los elementos paratextuales, enfatizando en la naturaleza social de los mismos, puesto que juegan un papel en la construcción del sentido del texto y al mismo tiempo arrojan luz sobre el sentido de la actividad traductora en determinadas culturas (YUSTE FRÍAS, 2012). En el programa del $1^{\circ}$ Congreso Internacional de Traducción e Interpretación de lenguas ibéricas, Yuste Frías (2018) señaló que el término paratraducción ha encontrado su aplicación metodológica en tres niveles: el empírico, gracias a análisis de paratextos verbales y no verbales vinculados al texto original; el sociológico, a través del estudio de agentes, procedimientos, normas e instituciones ligadas a la traducción; y el discursivo, en la discusión sobre los discursos en torno a la traducción, su funcionamiento y su conceptualización.

Basar la construcción del estudio que aquí presentamos en la noción de paratraducción nos parece necesario pues lo que se busca es hacer una lectura y un análisis del paratexto de traducción que revela un posicionamiento ideológico asumido por parte de los agentes de paratraducción de un texto que, desde la perspectiva de un observador extranjero, tocaba su propia identidad. De la reflexión de Garrido Vilariño (2012) en torno a la paratraducción y su papel de representación ideológica, en estas líneas resaltamos que, si la ideología presente en los paratextos puede ser distinta a la del texto, consecuentemente puede ser distinta entre el original y la traducción, dado que el espacio paratextual de ambas entidades tiene una función ideológica dada por las condiciones históricas, sociales y culturales del entorno.

Pretendemos aplicar el concepto de paratraducción a través de la identificación y del comentario de los elementos que en diversos momentos sirvieron las funciones de presentar, comentar e influenciar negativamente la recepción en México de la obra Life in Mexico de Frances Calderón de la Barca. En este trabajo, es especialmente revelador pensar en la paratraducción como "La necesidad de un posicionamiento ético, político, ideológico, social y cultural ante el acto nada inocente de traducir porque lo que está 'cerca de', 'al lado de', 'junto a', 'ante', 'frente a', 'en', 'entre' o 
incluso 'al margen de’ la traducción resulta ser la propia vida [...]" (YUSTE FRÍAS, 2015, p. 334).

Nosotros añadiríamos que en la traducción se vuelve necesario (para)traducir la propia identidad. Con base en la conceptualización del paratexto y en la noción de paratraducción para orientar nuestra atención hacia los agentes de traducción, nos proponemos presentar el texto original para proceder a exponer el corpus de elementos paratextuales.

\section{MADAME CALDERÓN DE LA BARCA Y LIFE IN MEXICO}

Frances Erskine Inglis, conocida como Madame Calderón de la Barca o Marquesa Calderón de la Barca, nació en Edimburgo en 1806 en el seno de una familia noble. En 1835 se casó con Ángel Calderón de la Barca, quien fungió como el primer embajador plenipotenciario de España en México tras el reconocimiento de la independencia. La pareja residió en México de 1839 a 1842 y desde que se embarcaron, Frances inició una correspondencia en la que relataba su estancia con su familia radicada en Boston. Durante su estancia, Frances Calderón de la Barca no solamente se sirvió de su experiencia para formarse la imagen de México que describía en sus relatos, sino que, como señala Méndez Rodenas (2014), leyó las memorias y ensayos de otros viajeros extranjeros, entre ellos el de Alexandre Humboldt. Además, Calderón de la Barca menciona en sus cartas los libros Historia antigua de México de Francisco Javier Clavijero y Life in Mexico in 1827 de Henry G. Ward y algunas publicaciones periódicas locales como El mosaico mexicano del editor Ignacio Cumplido.

La autora seleccionó 54 de sus cartas que preparó para publicación eliminando los nombres propios incluido el de ella misma como autora. En la portada se presenta como M_e C_n de la B_a. De acuerdo con Burrola Encinas (2019) el reparo en utilizar su nombre en obras cuya autoría es reconocida denota una relación entre la mujer y la escritura que era desventajosa en comparación con la del hombre en ese periodo. Las cartas de Frances fueron publicadas en 1843 con el título Life in Mexico en Boston por la editorial Charles C. Little and James Brown y en Londres por la editorial Chapman and Hall, la misma en donde publicaba Charles Dickens. Para lograr la publicación de Life in Mexico en ambas editoriales es sabida la mediación del historiador norteamericano William Prescott, quien era amigo personal de los Calderón de la Barca y quien en el mismo año publicaría su famoso libro Historia de la conquista de México. De ambos libros, el primero tuvo una recepción por demás negativa en México, mientras el segundo gozó de buena fama y de una pronta 
traducción al español. Si en este artículo se incluye esta precisión sobre el libro de Prescott es con el objetivo de hacer notar la diferencia en la recepción que más adelante se expondrá al hablar de la traducción/paratraducción.

Según Burrola Encinas (2019), la obra de Madame Calderón al ser publicada como epistolario, constituye un discurso de compleja recepción, puesto que no posee el estilo y el método de otros relatos de viajeros cuyos textos gozaron de reconocimiento o, cuando menos, de mayor divulgación en el México decimonónico. Por otra parte, a diferencia de los contenidos en materia de recursos naturales y oportunidades de expansión para empresas extranjeras que acentuaban otros textos de viajeros, Life in Mexico dedica buena parte de sus descripciones de la población de distintas clases, la moda, la comida, la relación con la servidumbre y a la vida social que experimentó o que observó a la distancia la autora. Aunque a lo largo de sus cartas Frances Calderón describe el país casi siempre de manera positiva, también expresa su disgusto por el paisaje (sea urbano, rural, natural), por la comida, por los modales o incluso por el aspecto físico de algunos mexicanos:

By slow but sure degrees, we neared the shore, until Vera Cruz, in all its ugliness, became visible to our much-wearied eyes (p.70).

To me nothing can exceed the sadness of the aspect of this city and of its environs [...]. The scene may resemble the ruins of Jerusalem, though without its sublimity. The houses seemed blackened by fire; there is not a carriage on the streets [...] (p. 74).

Such a theatre! Dark, dirty, redolent of bad odours; the passages leading to the boxes so illlighted, that one is afraid in the dark to pick one's steps through them (p. 135).

The theatre is certainly unworthy of this fine city (p. 136).

They made us some chocolate with goat's milk, horrid in general, and rancid in particular (p. 94).

(en el teatro) the audience had been composed entirely of Gentuza, the common people, who were drinking brandy and smoking; so it was fortunate that we had not shown our faces there (p. 104).

On first arriving from the United States, where an ugly woman is a phoenix, one cannot fail to be struck at the first glance with the general absence of beauty in Mexico [...] The defects are that they are frequently too short and too fat, that their teeth are often bad, and their complexion not the clear olive of the Spaniards, nor the glowing brown of the Italians, but a bilious-looking yellow (p. 178).

The badness of the servants, is an unfailing source of complaint even amongst Mexicans; much more so amongst foreigners, especially on their first arrival. We hear of their addiction to stealing, their laziness, drunkness, dirtiness, with a host of other vices (p. 298).

Por otro lado, la autora no duda en exponer su molestia ante la presencia de los pobres y de su comportamiento:

Whilst I am writing a horrible lépero, with great leering eyes, is looking at me through the windows, and performing the most extraordinary series of groans, displaying at the same time a hand with two long fingers, probably the other three tied in. [...] The wretch! I dare not 
look up, but I feel that his eyes are fixed upon a gold watch and seals lying on the table. That is the worst of a house on the ground floor (p. 128).

The number of léperos was astonishing, greatly exceeding that of well-dressed pople (p. 224). As a contrast to the Señoras, with their over-dressed beauties, were the poor Indian women, trotting across the square, their black hair plaited with dirty red ribbon, a piece of woolen cloth wrapped about them, and a little mahogany baby hanging behind, its face upturned to the sky, and its head going jerking along, somehow without its neck being dislocated (p. 230). My maid asked her, why, being so poor, she had left a good place, where she got twelve dollars a month. "Jesus!" said she, "if you only knew the pleasure of doing nothing" (p. 299).

Según Arbeláez (1995) a pesar del prestigio fluctuante de Life in Mexico y de que su traducción completa al español tardó casi un siglo, actualmente es valorado como una narración que se adelantó a su época en la descripción de los usos y costumbres de las clases altas en contraste con la miseria de las clases bajas.

\section{LA TRADUCCIÓN/PARATRADUCCIÓN DE LIFE IN MEXICO}

Al realizar un rastreo de las traducciones al español de Life in Mexico, encontramos que en 1843 se tradujeron y publicaron cuatro cartas en el periódico liberal El siglo diez y nueve, en 1844 una carta más se publicó en la revista literaria $E l$ liceo mexicano y es hasta el siglo XX que encontramos traducciones de todas las cartas, publicadas en distintas ediciones en 1920, 1959 y 2007.

El siglo XIX fue un periódico de circulación nacional diaria entre 1841 y 1896 , considerado uno de los principales promotores de las luchas liberales. Inicialmente los editores señalaron en la introducción de la publicación que su objetivo era ser "el órgano de la opinión nacional, siempre justa y moderanda" (p. 1). Su columna editorial, titulada igual que el periódico fue dedicada a discutir temas de política y actualidad del país, mientras que la sección Variedades se dedicó a la literatura.

El día 28 de abril de 1843, El siglo XIX publicó la primera carta del libro bajo el encabezado que repetirá para cada una de las cartas "Variedades. Residencia en México durante dos años. Cartas escritas por Madama Calderón de la Barca. Traducidas del inglés". La traducción de esta primera carta es literal y reporta el contenido íntegro del original. Al término de la traducción se encuentra, como elemento paratextual, la columna editorial "El Siglo XIX. Residencia en México durante dos años" en la que el periódico expuso que se disponía a traducir y publicar el libro en entregas y explicó los motivos para emprender dicha tarea editorial:

[...] presenta el medio de corregir o abandonar las costumbres, abusos o vicios, que sin interesar de modo alguno en su mejor estar, deshacen o eclipsan a la vista del extranjero un carácter y buenas cualidades y a la vez el de rectificar los hechos descritos con error y el de desmentir la crítica que no esté fundada en la verdad (p.4). 
El día 30 de abril del mismo año, el Diario de Gobierno de la República Mexicana publicó una columna, sin título, antecedida únicamente por una viñeta en la que critica duramente la obra y la persona de Frances Calderón, su esposo Ángel Calderón y la intención de El Siglo XIX de traducirla y publicarla. Algunos extractos de esta columna dicen:

No acertamos a decidir cuál haya sido mayor imprudencia, si la de esa señora, comprometiendo el carácter diplomático de su marido, o la de los que se prestan a poner en manos de todos los mexicanos las injustas, apasionadas, virulentas diatribas con que la señora Calderón ha correspondido a la exquisita y benévola hospitalidad con que ella y su esposo fueron tratados por los generosos vecinos de México.

De esta manera se presta mérito a que en el trato con los extranjeros se vuelvan los mexicanos más reservados porque si han de recibir mal hasta de las personas a quienes hacen bien, justo será poner coto a las pruebas y demostraciones de un afecto tan mal pagado. Hemos dado una rápida lectura a una obra que contiene tan miserables pequeñeces, que solamente es pasable porque le ha prestado las gracias de su estilo y prohijándola Mr. Prescott, el aplaudido autor de la historia de Isabel y de Fernando el católico. Desde luego se percibe que pertenece a la Sra. Calderón, lo que no puede pertenecer más que a una mujer de las que los ingleses llaman medias azules, es decir, un talento tan frívolo para la literatura, como para todos los asuntos que puedan encerrarse en la dilatada esfera del coquetismo.

[...] a todos ha faltado la Sra. Calderón y ha arrostrado también a su marido porque publicando ella cosas que no pudo saber más que de él, lo descubre como frívolo y ligero, y nada merecedor del alto encargo que se confiara, no menos a sus talentos que a su probidad pública, cualidades que esencialmente recomiendan a un ministro que sea caballero.

Haremos, por último, una caritativa advertencia a los editores del Siglo, y es que podrán ser demandados en juicio por las injurias que publiquen [...] (p.4).

Este epitexto es evidencia de una práctica de censura que, además de la amonestación a un exitoso periódico privado con circulación nacional y de la denostación de personajes públicos por vía de sus obras, refleja un ánimo polemista y oficialista en su intención de orientar el discurso que en torno a México se estaba formando en los primeros años de vida independiente. A pesar de la caritativa advertencia, el 14 de mayo El Siglo XIX publicó la traducción íntegra y literal de la segunda carta del libro. Después de la traducción, volvemos a encontrar como paratexto la columna editorial en la que el periódico transcribe algunos párrafos de la publicación del Diario de Gobierno y argumenta que no desea una contienda periodística y que continuará publicando las cartas puesto que:

Estamos persuadidos de que si un escrito honra a un país cualquiera, su publicación en él es útil porque el elogio estimula siempre a conservar o mejorar los objetos elogiados, y si lo deshonra, no solamente es útil sino necesaria, útil porque si la crítica es justa, corrige las costumbres, las cosas y los hombres; y si injustas su publicación facilita los medios de impugnar aquella con razón, con honor y con provecho; y necesaria porque sin conocer la crítica justa, no puede caber la corrección, y sin conocer la injusta, es imposible la defensa (p. 4).

Además, la publicación indica que se compromete a: 
[...] hacer las anotaciones, ya disminuyendo hechos erróneos o acusaciones infundadas contra la nación, ya rectificando los mal comprendidos, ya, en fin, modificando la crítica sobre objetos generales que juzguemos excesivos. Con respecto a la que se ejerce contra algunos individuos, creemos deber dar la contestación a los propios interesados, porque tratándose de la propia defensa, nadie mejor que ellos podrían pasar de ese apreciable derecho, obligándonos por lo mismo a publicar cuanto se escribiese sobre la materia, siempre que en los remitidos que se nos dirigiesen se conserve la decencia debida (p. 4).

Con esta reacción, observamos que, si bien el periódico no recula en su intención de publicación, sí revela aspectos de su actividad paratraductora al anticipar que dirigirá la lectura de Life in Mexico no sólo a través de comentarios en columnas posteriores a la traducción, sino mediante la modificación del texto original. Es interesante notar que este paratexto también invita a los lectores a participar como agentes paratraductores con el envío de remitidos.

El 21 de mayo el periódico publicó la tercera carta, nuevamente de manera literal y completa. La única diferencia con respecto a las dos anteriores es que la columna editorial no fue dedicada a discutir la traducción. Finalmente, el 24 de mayo se publicó la cuarta carta, también completa y literal y, otra vez, sin ninguna columna que la comentara posteriormente. Aunque se acompaña de la leyenda "Continuará", el periódico detuvo la publicación del libro sin mencionar nada al respecto en sus posteriores números. Es notable que a partir de la aparición del paratexto en el que se compromete a corregir el original, las siguientes dos traducciones siguen siendo literales y no omiten ninguna información, aun cuando en la cuarta carta la autora expresa su disgusto por la fealdad de la ciudad de Veracruz.

Más de un año pasaría para que algún proyecto editorial mexicano se volviera a ocupar de Life in Mexico. En la segunda mitad de 1844 apareció en la revista literaria El liceo mexicano la traducción de la novena carta bajo el título "Carta novena sobre México. Por Madama Calderón de la Barca" y, al igual que todos los artículos de la revista, inicia con una letra capitular adornada con motivos florales. Esta revista, dirigida por José Mariano Lara señaló en su introducción que sus fines principales eran la observancia de la utilidad y la moralidad. La traducción es completa y literal, y se incluye una nota al pie tras un fragmento de descripción de una corrida de toros.

El texto original dice: "Occasionally the picador would catch hold of the bull's tail, and passing it under his own right leg, Wheel his horse round, forcé the bullock to gallop backwards, and throw him on his face" (p. 151).

La traducción se lee: "Algunas veces agarraba el picador la cola del toro y pasándola por debajo de su propia pierna derecha, volvía las riendas a su caballo 
para forzar al bruto a galopar hacia atrás y le derribaba de cabeza" Con la nota al pie: "Esto se llama coleur 'à la Calderon"" (p. 309).

Probablemente se trata de un gesto irreverente por parte del traductor ante la descripción que hace Frances Calderón de lo que en el rodeo mexicano se llama colear.

La traducción está firmada por L. M. de C., es decir, Luis Martínez de Castro, quien en el mismo año firma para el Liceo Mexicano un artículo titulado "Isidoro Lowenstern y sus memorias sobre México" en la que encontramos un epitexto que nos refiere a Life in Mexico:

[...] es un absurdo imperdonable el confundir, aunque solo sea en el nombre, al humilde pintor de frisos y fachadas, con el ingenioso artista [...] Esto no obstante, el común de las gentes suele dar a entrambos individuos el nombre de pintores, con notorio agravio a la sana razón. Pues igual injusticia se comete, en mi humilde concepto, apellidando indistintamente viajeros a todos los que viajan [...]. A mí, al menos me parecerá siempre una profanación el confundir a madama Stael o a Lady Montagne con madama Calderón, y sobre todo a Humboldt con Isidoro Lowenstern (p. 18).

Es hasta 1920 que encontramos una traducción íntegra publicada por la Librería de la viuda de Ch. Bouret. Se trata de la traducción de Enrique Martínez Sobral acompañada por un breve prólogo de Manuel Romero de Terreros en el que elogia el contenido del original. La portada indica que el libro es de Madame Calderón de la Barca. Es interesante notar que el mismo prólogo acompaña a la edición norteamericana de Life in Mexico de 1954 por Everyman's Library. Romero de Terreros destaca las descripciones positivas de las figuras públicas, la arquitectura y la vida social que Calderón de la Barca plasmó en su libro e incluso enfatiza las cualidades de la autora como se muestra en el párrafo final del prólogo: "Que era inteligente, culta y una excelente jueza del carácter, así como una verdadera amante de la naturaleza y una aguda observadora de los usos y costumbres, es evidente en sus cartas, que constituyen, por consenso, una narrativa de lo más entretenida y verdaderamente deliciosa $[\ldots]^{\prime \prime}$ (s. p.).

Por su parte, Editorial Porrúa publicó en 1959 La vida en México, traducción y prólogo de Felipe Teixidor. La portada presenta a la autora como Madame Calderón de la Barca. Esta edición es la de mayor difusión en México y el texto de Teixidor, el más citado en trabajos académicos por ser un estudio completo sobre la autora. Dada la abundancia de artículos en torno a este prólogo que superan los objetivos del estudio que aquí se presenta, orientamos nuestra atención al paratexto en la contraportada, en el que se lee:

La vida en México, durante una residencia de dos años en ese país, de Frances Erskine Inglis, ocupa un lugar sobresaliente en la extensa nómina de libros que son llamados de "viajes", a 
pesar de que muchos de los extranjeros que visitaron el país no lo hicieran en calidad de tales, como no lo hizo esta autora [...]. El 28 de abril de 1842 la señora Calderón de la Barca firmó la última de sus cartas. No se dio cuenta, al hacerlo, que había puesto punto final a uno de los mejores libros que haya escrito sobre México un extranjero.

Finalmente, la traducción más reciente al español es de Raquel Brezmes publicada por la editorial española Rey Lear en 2007. Esta edición es la única de las traducciones que presenta a la autora como Frances Erskine Inglis Marquesa de Calderón de la Barca e incluye una breve presentación firmada por "El Editor" de la que tomamos un fragmento que revela el tono positivo que adquirió el retrato de México en esta obra:

Desde que su libro La vida en México apareciese publicado en 1843 en Boston y Londres, apadrinado por el historiador norteamericano William H. Prescott, los lectores mexicanos no han dejado de leerlo. La indignación inicial con que lo recibieron se ha enfriado con el paso del tiempo, hasta convertirse en admiración hacia uno de los textos imprescindibles para comprender la agitada y peculiar sociedad de ese país a mediados del siglo XIX (s. p.)

Estas tres traducciones integrales de Life in Mexico, a diferencia de las traducciones parciales anteriores, incluyen la traducción del paratexto que acompañaba al original, el prefacio de Prescott:

The present work is the result of observations made during a two years' residence in Mexico, by a lady, whose position there made her intimately acquainted with its society, and opened to her the best sources of information in regard to whatever could interest an enlightened foreigner.

It consists of letters written to the members of her own family, and, really, not intended originally -however incredible the assertion- for publication. Feeling a regret that such rich stores of instruction and amusement, from which I have so much profited, myself, should be reserved for the eyes of a few friends only, I strongly recommended that they should be given to the world. This is now done, with a few such alterations and omissions as were necessary in a private correspondence; and although the work would derive more credit from the author's own name, than from anything which I can say, yet as she declines prefixing it, I feel much pleasure in making this statement by way of introduction to the public.

William H. Prescott.

Boston, December 20, 1842 (s.p.)

Las diferencias en la traducción de este paratexto entre las tres ediciones son meramente estilísticas, por lo que, como hemos visto, los agentes paratraductores del siglo XX y XXI centraron su actividad en la escritura de textos introductorios, en la manera de presentar el nombre de la autora en la portada y en la información contenida en la contraportada. Los agentes paratraductores del siglo XIX, en cambio, limitaron su actividad traductora, pero se extendieron en el comentario en torno a la obra y a su autora. 
Estos paratextos dan cuenta de que Life in Mexico, además de relatar la vida en el país, reflejó la vida de los agentes de paratraducción, sus prácticas editoriales relativos a la polémica, a la censura, al elogio y su observación permite descubrir cómo esas prácticas se transforman a lo largo del tiempo.

\section{CONCLUSIONES}

Los paratextos expuestos son una muestra del fenómeno que en este trabajo pretendemos explorar: el papel de la literatura de viajes y su paratraducción como metáfora de un espejo identitario. La indagación aquí presentada nos permite evidenciar una vez más que la traducción difícilmente es imparcial. Los epitextos y peritextos de las primeras traducciones mexicanas de Life in Mexico revelan que las impresiones que los extranjeros difundían sobre el país provocaba en la prensa local reacciones por parte de editores y traductores que exponían sus posturas y sus ideologías sobre la identidad de la nación. En esas primeras traducciones de fragmentos, la actividad traductora parece un pretexto para que los medios impresos compartieran con sus lectores un posicionamiento, con lo que la traducción fungió un papel político. Las traducciones del texto completo, aunque fueron publicadas décadas después del original, no son menos inocentes por no condenar el contenido o a la autora. La traducción mantiene una función ideológica que matiza los anteriores paratextos y guía la experiencia lectora hacia el reconocimiento de las observaciones hechas por Frances Calderón de la Barca como un retrato de la sociedad mexicana decimnónica y hacia el elogio a la autora.

Las reflexiones aquí presentadas conforman con el trabajo de Bastin, Echeverri y Campo (2013), Garrido Vilariño (2007) y Correa Larios (2018) en el sentido de que los agentes traductores y paratraductores no actúan en aislamiento, sino que sus acciones son producto del contexto social, cultural, político, económico que ejerce influencias en ellos a nivel personal y laboral. A modo de apertura para próximas investigaciones, se prevé que la revisión de la actividad traductora en diferentes publicaciones periódicas del México decimonónico podrá arrojar luz para entender la historia de la formación identitaria a partir de la historia de la paratraducción de literatura de viajes.

\section{REFERENCIAS}

ARBELÁEZ, M. S. (1995). La vida en México. Una breve historia. Historias. Revista de la Dirección de Estudios Históricos (34), pp. 71-88. 
BATCHELOR, K. (2018). Translation and Paratexts. Routledge.

BASTIN, G., ECHEVERRI, A. OCAMPO, A. (2013). Traducción y las primeras repúblicas en Latinoamérica. En N. Castro Ramírez, Traducción, identidad y nacionalismo en Latinoamérica. Bonilla Artigas, pp. 45-76.

BURROLA ENCINAS, R. M. (2019). El viaje a México de Madame Calderón de la Barca. Perifrasis. Revista de Literatura, Teoría y Crítica, pp. 24-42.

CALDERON DE LA BARCA, F. (1954). Life in Mexico. Londres: Everyman's Library.

CALDerón DE LA BARCA, M. (1920). La vida en México. (E. Martínez Sobral, Trad.) México: Bouret.

CALDERÓN DE LA BARCA, M. (1959). La vida en México, durante una residencia de dos años en ese país. México: Porrúa.

CARNEIRO RODRIGUES, C. (2008). Traducao e viagem. Revista do GEL. S. J. do Rio Preto, 5(1), pp. 69-79.

CASTRO, N. (2019). Translation in Central America and Mexico. En Y. Gambier, \& U. Stecconi, A World Atlas of Translation. John Benjamins Publishing Company, pp. 419-442.

COLOMBI NICOLIA, B. (2006). El viaje y su relato. Latinoamérica, 43(2), pp. 11-35.

CORREA LARIOS, O. (2018). Traducción de literatura de viaje en El álbum mexicano (1849): un análisis sobre el papel de la traducción como espejo de identidad. Verbum et Lingua, 11, pp. 64-74.

CORREA LARIOS, O.; HARKINS KENNING, M. (2018). El lugar de la traducción en un royecto de difusión literaria del México independiente: El álbum mexicano (1849). En A. M. D'Amore; N. Castro Latinoamérica traducida: aproximaciones recientes desde un campo en construcción. Bonilla Artigas Editores, pp. 165-182.

COSTELOE, M. (2006). William Bullock and the Mexican Connection. Mexican Studies/ Estudios Mexicanos, 22(2), pp. 275-309.

COVARRUBIAS, J. E. (1998). Visión extranjera de México, 1840-1867 1. El estudio de las costumbres y de la situación social. México: Universidad Nacional Autónoma de México.

CRONIN, M. (2006). Translation and Identity. Nueva York: Routledge. 
Diario de Gobierno de la República Mexicana. (1843). México: Impresa de Ignacio Cumplido.

DOS SANTOS, F. E., \& ALVARADO, E. (2013). La traducción literaria y el compromiso ético del traductor. Mutatis Mutandis, 6(1), pp. 4-21.

El liceo mexicano. (1844). México: Imprenta de José Mariano Lara.

El siglo diez y nueve. (1843). México: Imprenta de Ignacio Cumplido.

ERSKINE INGLIS, F. (2007). La vida en México durante una residencia de dos años en ese país. (R. Brezmes, Trad.) Rey Lear.

ETTE, O. (2008). Literatura en movimiento: Espacio y dinámica de una escritura transgresora de fronteras en Europa y América. Madrid: Consejo Superior de Investigaciones Científicas.

GARRIDO VILARIÑO, X. M. (2007). Ideología y traducción. Lenguas en contexto(4), pp. $52-59$.

GARRIDO VILARIÑO, X. M. (2012). Análisis de la traducción/paratraducción de "Se questo è un uomo" al castellano. En A. Camps, La traducción en las relaciones ítalo-españolas: lengua, literatura y cultura. Barcelona: Publicacions i Edicions de la Universitat de Barcelona, pp. 379-392.

GENETTE, G. (1997). Paratexts: Tresholds of interpretation. (J. E. Lewin, Trad.) Nueva York: Cambridge University Press.

ILLADES, L. (2019). Marcos Arroniz: una respuesta a las visiones de alteridad de viajeros extranjeros sobre México y los mexicanos.Naveg@mérica. Revista electrónica editada por la Asociación Española de Americanistas (22), (en línea). Obtenido de https://revistas.um.es/ navegamerica/article/view/363611/258931

LÓPEZ DE MARISCAL, B. (2014). La escritura y el camino. Discursos de viajeros en el Nuevo Mundo. México: Bonilla Artigas.

MÉNDEZ RODENAS, A. (2014). Transatlantic Travels in Nineteentb-Century Latin America: European Women Pilgrims. Plymouth: Bucknell University Press.

ORTEGA Y MEDINA, J. A. (2015). Estudio preliminar a Seis meses de residencia y viajes en México. En M. C. González Ortiz, \& A. Mayer, Obras de Juan A. Ortega y Medina, 3. Literatura viajera. México: Universidad Nacional Autónoma de México, pp. 333-374. 
PAYÁS, G. (2013). Cuando la historia de la traducción sirve para revisar la historia. En N. Castro, Traducción, identidad y nacionalismo en Latinoamérica. México: Bonilla Artigas, pp. 23-44.

RAMÍREZ RODRÍGUEZ, R. (2013). Atisbo historiográfico de la literatura viajera decimonónica en México. Trashumante. Revista Americana de Historia Social, pp. 114-136.

ROMANO SUED, S. (2014). El dilema de la traducción. El viaje y la diáspora de la escritura. Transfer, 9(1), pp. 64-97.

YUSTE FRÍAS, J. (2011). Leer e interpretar la imagen para traducir. Trabalbos em Linguística Aplicada, 50(2), pp. 257-280.

YUSTE FRÍAS, J. (2012). Traducir la frontera en la frontera. En S. Cruces Colado, M. Del Pozo Triviño, A. Luna Alonso, \& A. Álvarez Lugrís, Traducir en la frontera. Granada: Atrio, pp. 435-448.

YUSTE FRÍAS, J. (2015). Paratraducción: la traducción de los márgenes, al margen de la traducción. D.E.L.T.A.(31), pp. 317-347.

YUSTE FRÍAS, J. (2018). Conferencias plenarias. Obtenido de Translbérica $1^{\circ}$ Congreso Internacional de Traducción e Interpretación de lenguas ibéricas: https://sites. google.com/site/transiberica2018/conferencias-plenarias/paratraduccion-un-nuevoproducto-en-el-catalogo-de-los-conceptos-traductologicos

Recebido: $7 / 5 / 2020$

Aceito: 21/7/2020

Publicado: $14 / 7 / 2020$ 